\title{
1. Introduction to counterfeit and falsified medicines
}

\section{RELEVANCE}

Counterfeiting ${ }^{1}$ is not a new phenomenon. Hailed as the second oldest profession in the world, ${ }^{2}$ counterfeiting has a long history. ${ }^{3}$ In fact, it has been known to exist for at least the past 2,000 years. Pliny the Elder described counterfeit coins as popular collectors' items for Romans ${ }^{4}$ and in 40-90 AD, Dioscorides, a Greek physician, pharmacologist and botanist, wrote about the detection of counterfeit drugs in his work entitled Materia Medica. Other Greco-Roman medical and natural history writers who have written about falsification of medicine include Theophrastus and Galen. ${ }^{5}$

Counterfeiting has survived the vicissitudes of times, but the forms of counterfeiting have transformed and multiplied. Be it counterfeiting of currency, wine, fine arts or luxury goods - all types of counterfeiting have negative reverberations on the economy, growth, employment and innovation. The latest survey conducted by the Organisation for Economic Co-operation and Development (OECD) and the European Union Intellectual Property Office (EUIPO) reported that the global trade in fake goods was worth almost half

1 Counterfeiting is commonly understood to mean 'to forge; to copy or imitate, without authority or right, and with a view to deceive or defraud, by passing the copy or tiling forged for that which is original or genuine'. See more in H.C. Black, J.R. Nolan and J.M. Nolan-Haley, Black's Law Dictionary (sixth edition). West Publishing Co. (1990) 349.

2 Frank Van Riper, Counterfeiting. Saturday Evening Post 250(7) (1978): 42-44. Academic Search Premier. Web. 8 Dec. 2012.

3 See further in E.W. Stieb, Drug Adulteration: Detection and Control in the 19th Century Britain, The University of Wisconsin Press (1966).

${ }_{4}$ K. Barry, Counterfeits and counterfeiters: The ancient world. In P.E. Chaudhry and A. Zimmerman, The Economics of Counterfeit Trade: Governments, Consumers, Pirates and Intellectual Property Rights. Springer Science and Business Media (2009) 7.

5 See further in E.W. Stieb, Drug Adulteration: Detection and Control in the 19th Century Britain The University of Wisconsin Press (1966). 
a trillion dollars per year. ${ }^{6}$ The OECD/EUIPO Report on Trade in Counterfeit Pharmaceutical Products $2020^{7}$ has indicated that the European Union (EU) governments stand to lose 1.7 billion euros in forgone revenue due to counterfeit medicines. Besides economic loss, serious types of counterfeit products, such as falsified medicines, fake automobile spare parts and counterfeit toys cause large numbers of mortalities across the globe. ${ }^{8}$ The consequences of use of falsified and counterfeit medicines can range from failure of the targeted treatment to development of drug resistance, and in the worst-case scenario it can result in early death. ${ }^{9}$ The threat of counterfeiting is often ignored in a society until a disaster hits and the consequences become obvious.

Tragedy begets attention. It took the Thalidomide disaster ${ }^{10}$ to shake up health regulation in Europe as well as the United States. Thalidomide was a drug that was marketed under the trade-name Contergan in West Germany in 1957, and was subsequently also marketed in Austria. This drug was prescribed to pregnant women to alleviate morning sickness and resulted in around 7,000 infants being born with a malformation of the limbs (phocomelia) in West Germany and Austria. ${ }^{11}$ Approximately 10,000 cases of infants born with phocomelia were reported around the world, and only 50 per cent of these infants survived, but with severe $\operatorname{limb}^{12}$ and other organ defects. ${ }^{13}$ This landmark case led to stricter and more comprehensive regulation of medicines, including over-the-counter (OTC) drugs, and resulted in a paradigm change in

6 OECD/EUIPO, Trade in Counterfeit and Pirated Goods: Mapping the Economic Impact. OECD Publishing, Paris (2016). The value of imported fake goods worldwide was estimated to be USD 461 million in 2013, compared to the total imports in world trade at USD 17.9 trillion. It was also reported that up to 5 per cent of goods imported into the EU are fakes.

7 OECD/EUIPO (2020), Trade in Counterfeit Pharmaceutical Products, Illicit Trade. Paris. OECD Publishing. https://doi.org/10.1787/a7c7e054-en.

8 The use of counterfeit medicines has resulted in the deaths of patients around the world. Such deaths were reported, for instance, in the USA, Canada and New Zealand. A.I. Wertheimer and P.G. Wang, Counterfeit Medicines: Policy, Economics, and Countermeasures (Vol. 1). ILM Publications (2012) 75-76.

9 Mohammad Sofiqur Rahman et al., The health consequences of falsified medicines - A study of the published literature. Tropical Medicine and International Health 23(12) (2018): 1294-1303.

10 A. Dally, Thalidomide: was the tragedy preventable? The Lancet 351(9110) (1998): 1197-1199.

11 W.G. McBride, Thalidomide and congenital abnormalities. The Lancet 278(7216) (1961): 1358 .

12 G.J. Annas and S. Elias, Thalidomide and the Titanic: reconstructing the technology tragedies of the twentieth century. American Journal of Public Health 89(1) (1999): 98-101.

13 G. Koren, A. Pastuszak and S. Ito, Drugs in pregnancy. New England Journal of Medicine 338(16) (1998): 1128-1137. 
the regulation of medicines. In the EU, the regulation of the pharmaceutical sector became stricter ${ }^{14}$ as an aftermath of the Thalidomide tragedy when the potential harm from inadequately regulated medicinal products was revealed. Unlike the aftermath of natural disasters, the fatalities caused by counterfeiting products can be prevented. ${ }^{15}$ It is imperative to address the issue of counterfeiting and falsification of medicines in order to avert tragedies of Thalidomide proportions.

It has become evident that with relatively little investment it is possible to amass high volumes of profits by engaging in counterfeiting and falsification of medicines. The cost accrued to the counterfeiter associated with the manufacturing of fake pills is negligible as compared to the profits that are accumulated by the counterfeiter, as a result of the sale of each counterfeit pill. The International Institute of Research against Counterfeit Medicine (IRACM) has reported that an investment of USD 1,000 generates USD 20,000 in the trafficking of heroin or a return of USD 43,000 for counterfeit cigarettes. However, with the investment of USD 1,000 in counterfeit pharmaceuticals, a return of USD 500,000 can be expected. ${ }^{16}$ In fact, Interpol values the annual turnover from pharmaceutical crime at USD 75 million. ${ }^{17}$ Counterfeiting in the pharmaceutical sector is attractive for criminals, not only because of the relatively easy profits associated with counterfeiting but also due to the low probability of being detected. Even if the counterfeiters are discovered, the penalty for counterfeiting of medicines is minimal as compared to other offences. In the EU, the average sentence for a pharmaceutical crime is less than three years in prison. ${ }^{18}$

Therefore, counterfeiting and falsification of medicines and medicinal products continues to be an attractive option for the get-rich-quick Harry Limes of

14 G. Permanand, EU Pharmaceutical Regulation: The Politics of Policy-Making. Manchester University Press (2006).

15 Had the appropriate legal structures and systems been effective and in place.

16 EUIPO. Synthesis Report on IPR Infringement 2018. ISBN 978-92-9156-230-5 doi: 10.2814/833376 TB-04-17-771-EN-N. European Union Intellectual Property Office (2018) 17.

17 Office of Harmonization in the Internal Market and Europol. Situation Report on Counterfeiting in the European Union - A Joint Project between Europol and the Office for Harmonization in the Internal Market (2015) 11.

18 In Slovakia, the penalty is three years and in Poland, the prison sentence for pharma crime is currently only two years, as reported by the Office of Harmonization in the Internal Market and Europol. See Europol and OHIM. Situation Report on Counterfeiting in the European Union - A Joint Project between Europol and the Office for Harmonization in the Internal Market (2015) 39. 
the world. ${ }^{19}$ As aptly portrayed in The Third Man, a widely acclaimed British film, ${ }^{20}$ one of the greatest villains asserted that it was his ambition that got him far. ${ }^{21}$ Nefarious intention in conjunction with availability of a wide number of channels to manufacture and market counterfeit and falsified medicinal products have propelled the growth of counterfeit and falsified medicines (henceforth referred to as 'CFM'). Alarming to note, CFM can find their way into the hands of potential patients through a multiplicity of routes.

Contrary to popular belief, it is not only drugs such as weight loss tablets, erectile dysfunction medication, or steroids for muscle enhancement that are targeted for counterfeiting. In fact, in the past decade lifesaving medicines have increasingly become the prime prey of counterfeiters. ${ }^{22}$ The most plausible reason for picking lifesaving medicines is that lifesaving medicines are expensive, essential, and remain in demand for a consistently longer time. Moreover, the morbid reality is that terminally ill patients do not leave a trace behind for detection. Therefore, cancer treatment medications, diabetes medicines, as well as medical devices and equipment, have ironically become a safe bet for counterfeiters. ${ }^{23}$

The rising numbers of counterfeit products in the pharmaceutical industry place public health and safety at risk, as is evident across the globe. ${ }^{24}$ In 1985 , the World Health Organization (WHO) recognized counterfeit medicines as a global problem. ${ }^{25}$ The $\mathrm{WHO},{ }^{26}$ the International Police Organization (Interpol), ${ }^{27}$ and academic circles $^{28}$ have acknowledged the exponential

19 In the novel The Third Man by Graham Greene and the film by the same name, which in 2017 was voted the second best British film ever made, the villain Harry Lime engages in diluting stolen penicillin and selling it on the black market. Dave Calhoun, Tom Huddleston, David Jenkins, Derek Adams, Geoff Andrew, Adam Lee Davies, Paul Fairclough, Wally Hammond, Alim Kheraj and Phil de Semlyen, The 100 best British films. Time Out (10 September 2018) https://www.timeout.com/london/ film/100-best-british-films\#tab_panel_10 accessed 9 July 2019.

20 Ibid.

21 American Film Institute. AFI's 100 years... 100 heroes \& villains (4 June 2003) https://www.afi.com/100years/handv.aspx accessed 9 July 2019.

22 See Chapter 2 for three concrete examples.

23 Ibid., 13.

24 E.A. Blackstone, J.P. Fuhr Jr and S. Pociask, The health and economic effects of counterfeit drugs. American Health and Drug Benefits 7(4) (2014).

25 World Health Organization (WHO). Substandard/spurious/falsely labelled/falsified/counterfeit Medical Products: Report of the Working Group of Member States. Geneva. WHO (2012).

26 Ibid.

27 Interpol. Operation Pangea VII Report. Lyon. Interpol (2014).

28 E.A. Blackstone, J.P. Fuhr Jr and S. Pociask, The health and economic effects of counterfeit drugs. American Health and Drug Benefits 7(4) (2014). 
increase in worldwide trade of counterfeit goods. Interpol reported the same in $2014^{29}$ and the WHO in 2012. ${ }^{30}$ In 1985 , the WHO recognized public health issues connected with counterfeit medicines and by 2010 , they had revealed that the global counterfeit market had a turnover of USD 75 billion. ${ }^{31}$ Recent estimates indicate that the global market share of counterfeit pharmaceuticals is at USD 200 million, thereby emphasizing a 90 per cent increase in revenues since 2005. ${ }^{32}$ Moreover, a recent study conducted on 5,000 EU citizens in five countries cast light on the fact that 5 per cent of consumers suspect that they have been at the receiving end of counterfeit prescription drugs, whereas 1 per cent of consumers were sure that they had actually received a counterfeit prescription medicine. This estimate implies that nearly 12.8 million consumers were at risk of consuming counterfeit medicines in these countries. ${ }^{33}$

The issue of counterfeit medicine has been addressed in various forums. Since the 1980s, a global congress on combating counterfeiting and piracy has been organized at the $\mathrm{WHO}^{34}$ by a public-private partnership with representatives from Interpol; the World Customs Organization (WCO); the World Intellectual Property Rights Organization (WIPO); the International Chamber of Commerce (ICC) / Business Action to Stop Counterfeiting and Piracy (BASCAP) Initiative; and the International Trademark Association (INTA). ${ }^{35}$ As will also become apparent from the subsequent chapters, efforts have been made at international, regional and national levels to counter this problem. Nevertheless, the efforts have not proved to be adequate.

The popular belief that counterfeit medicine is a problem primarily in Asia and Africa is contestable. There is evidence that suggests that counterfeit and falsified medicines affect the developed and developing world almost equal-

29 Interpol Operation Pangea VII Report, Lyon. Interpol (2014).

30 World Health Organization (WHO), Substandard/spurious/falsely labelled/falsified/ counterfeit Medical Products: Report of the Working Group of Member States. Geneva. WHO (2012).

31 Ibid.

32 IRACM, Counterfeit Medicines and Criminal Organizations, Paris. IRACM (2013).

33 G. Jackson, S. Patel and S. Khan. Assessing the problem of counterfeit medications in the United Kingdom. International Journal of Clinical Practice 66(3) (2012): 241-250.

${ }_{34}$ WHO. WHO launches task force to fight counterfeit drugs. In Bulletin of the World Health Organization 84(9) September (2006): 685-764.

35 The Global Congress on Combating Counterfeiting and Piracy, where business leaders, law enforcement officers, inter-governmental authorities and non-governmental organizations were represented to discuss vital questions pertaining to counterfeiting, including the question about the evolving nature of counterfeiting and the impact on the future of public health and safety. 
ly. ${ }^{36}$ A recent study presenting the findings of a survey of literature discussed incidents of serious harm, injury or deaths due to use of falsified medicines across the globe. In the study, it was deduced that 56.3 per cent of incidents occurred in the developing countries and 43.7 per cent in the developed countries. These recorded incidents comprised 7,200 casualties, including 3,604 deaths. ${ }^{37}$ Therefore, it is imperative to address the issue of counterfeiting and falsification in both the developing as well as the developed countries. In this book, the focus is on counterfeiting and falsification in the pharmaceutical sector of the EU. Through this book, it is emphasized that the EU is just as vulnerable as other parts of the world and this is highlighted through three case studies, discussed in Chapter 2.

\section{GLOBAL INITIATIVES}

Counterfeiting and falsification of medicines is a matter of global concern. Evidence shows that most CFM cases involve several countries and it is not possible to predict which permutations and combinations of countries would form from case to case. Therefore, a global agreement (worldwide) rather than international agreements (involving two or more nations) would appear to be the most appropriate way forward. However, conducting an analysis of international agreements has its merits as it may help to situate the problem of counterfeiting of medicines in a global perspective, as well as to assess if there are some unique features that could spark change or serve as inspiration to strengthen the legal framework in the EU.

The agreement on Trade-Related Aspects of Intellectual Property Rights (TRIPS), negotiated in 1994, is the only global agreement in the realm of intellectual property rights (IPRs) that is widely recognized and implemented. Since TRIPS, none of the newer agreements have been successful. Specifically, the failure of the Anti-Counterfeiting Trade Agreement (ACTA) ${ }^{38}$ in 2012 after

36 Mohammad Sofiqur Rahman et al., The health consequences of falsified medicines - A study of the published literature. Tropical Medicine and International Health 23(12) (2018): 1294-1303.

37 Ibid.

38 ACTA was composed of the United States, the European Community, Switzerland, Japan, Australia, Republic of Korea, New Zealand, Mexico, Jordan, Morocco, Singapore, the United Arab Emirates and Canada. Anti-Counterfeiting Trade Agreement, 2011 (ACTA). ACTA final text, May 2011, retrieved from http://www .mofa.go.jp/policy/economy/i_property/pdfs/acta1105_en.pdf accessed 6 April 2017. 
years of negotiation ${ }^{39}$ and the inadequacy of the Medicrime Convention, ${ }^{40}$ indicated by the fact that only a handful of countries have ratified it, illustrate the lack of success of any worldwide agreement on the issue of CFM.

Even though ACTA failed, it is worthy of consideration in order to extrapolate lessons that can be learned, especially in the context of criminal measures that can be instituted for violation of IPRs, including against counterfeit medicines. This is important because the Medicrime Convention does not govern IPR violations but only handles the issue from the perspective of public health and safety. There were questions raised regarding the reasons underpinning the inception of ACTA ${ }^{41}$ the associated inadequacy or insufficiency of TRIPS and the absence of ACTA negotiation under the World Trade Organization (WTO) regime or any other internationally recognized forum. Some of the answers to the questions raised lie in the area of international politics and diplomacy rather than in the purely legal regulatory arena, for instance, lack of transparency ${ }^{42}$ in the process of negotiations and forum-shifting, ${ }^{43}$ where developed countries dominated the process and developing countries and their interests were not satisfactorily represented.

ACTA had the broad aim to combat counterfeiting in the context of IPRs in general and was not specifically tailored to the need to combat counterfeiting and falsification of medicines. An analysis of the main provisions of ACTA and the comparison of ACTA with the EU legal instruments governing CFM reveals that civil measures are pre-existing in the Enforcement Directive, ${ }^{44}$ and the Customs Regulation adequately covers the border measures..$^{45}$ None of the harmonized legal instruments at the EU level addresses the criminal measures that ACTA provided for. ${ }^{46}$ ACTA addressed the criminal enforcement of

39 ACTA was a multinational plurilateral trade agreement conceived in 2010. The main aim of articulating an agreement with global application was to combat counterfeiting and to be instrumental in enforcement of IP rights by establishing global standards.

40 Council of Europe Convention on the Counterfeiting of Medical Products and Similar Crimes Involving Threats to Public Health, 2011, CETS No. 211. See Chapter 5 for more details.

${ }_{41}$ C.R. McManis, The proposed Anti-Counterfeiting Trade Agreement (ACTA): two tales of a treaty. Hous. L. Rev. 46 (2009): 1235.

42 D.S. Levine, Transparency soup: The ACTA negotiating process and 'black box' law-making. American University Journal of International Law and Policy 26(3) (2011): 811 .

43 B. Mercurio, Beyond the text: the significance of the Anti-Counterfeiting Trade Agreement. Journal of International Economic Law 15(2) (2012): 361-390.

44 Articles 8 to 11 Directive 2004/48/EC.

45 Articles 17 to 26 Regulation No. 608/2013.

46 Although the Council of Europe initiative, the Medicrime Convention, provides for the criminalization of counterfeiting of medicinal products, it has not been ratified by all the Member States as yet. See Chapter 5 for a detailed discussion. 
IPRs in general from an intellectual property (IP) perspective, an area which is still not harmonized at the EU level. In order to fill this conspicuous gap with respect to criminal enforcement of IPRs, ACTA can serve as a blueprint when harmonization of IP law with regard to criminal enforcement of IPRs is reconsidered, especially in the EU, since it has articulated the criminal offences associated with violations of IPRs under Article 23. While, on the one hand, most attempts at global agreements are not seeing fruition, on the other hand, there is a marked increase in the number of multilateral, plurilateral and bilateral agreements. This is symptomatic of a developing dissatisfaction with, and inadequacy of, international agreements in the IPR domain. For instance, the EU and Canada are working on a Comprehensive Economic and Trade Agreement (CETA) covering classic free trade issues. ${ }^{47}$ In 2012, a Regional Comprehensive Economic Partnership (RCEP) ${ }^{48}$ began to take form between ASEAN Member States and Australia, China, India, Japan, Korea and New Zealand. RCEP, which is a large-scale free trade agreement, has also dedicated a chapter to IP enforcement. ${ }^{49}$ In the Pacific region, the Comprehensive and Progressive Agreement for Trans-Pacific Partnership (CPTPP) ${ }^{50}$ has been negotiated between the members of the P4 free trade agreement of 2005 (Brunei, Chile, New Zealand and Singapore) and Australia, Canada, Japan, Malaysia, Mexico, Peru and Vietnam. CPTPP also contains provisions on IP enforcement. ${ }^{51}$

The various multilateral and bilateral agreements are either recently negotiated or are in the process of being negotiated. As the titles of the various

47 CETA is an agreement being negotiated between Canada and the EU to promote trade. The European Parliament has approved it but the approval of the EU national parliaments is awaited. European Commission, Press Release (IP/17/270). CETA entered into force on a provisional basis on 21 September 2017. It implies that most of the agreement applies but national parliaments need to approve CETA before it can take full effect.

48 RCEP is a regional free trade agreement being negotiated by the Association of Southeast Asian Nations (ASEAN) (Brunei, Cambodia, Indonesia, Laos, Malaysia, Myanmar, the Philippines, Singapore, Thailand, Vietnam) and six other nations with which ASEAN has pre-existing free trade agreements, the other nations being Australia, China, India, Japan, South Korea and New Zealand.

49 M.K. Lewis, The TPP and the RCEP (ASEAN6) as potential paths toward deeper Asian economic integration. Asian J. WTO and Int'l Health L and Pol'y 8 (2013): 359.

50 Comprehensive and Progressive Agreement for Trans-Pacific Partnership (СРТPР) - a trade agreement between Australia, Brunei, Canada, Chile, Japan, Malaysia, Mexico, New Zealand, Peru, Singapore and Vietnam. It contained both tariff and non-tariff barriers to trade and it set up investor-state dispute settlement.

51 F. Fergusson, W.H. Cooper, R. Jurenas and B.R. Williams, The Trans-Pacific Partnership negotiations and issues for congress. Current Politics and Economics of South, Southeastern, and Central Asia 22(2) (2013): 209. 
agreements suggest, these are trade agreements, which focus on economic partnerships. In general, the trade and investment agreements (TIAs) have been criticized for their potential negative impact on public health. The effect of these trade agreements will also be felt on those countries that are not signatories to the agreements since by default these trade agreements would be setting the standard and rules for rest of the world. Adherence to these rules would be inevitable if a country would like to remain competitive in global trade. In addition, the formation of the mega-regional trade agreements coincides with the timing of an increase in the number of trade disputes that concern public health protection.

The main focus of analysis of multilateral and bilateral agreements has been with reference to counterfeiting in the pharmaceutical sector. The main parameters to determine the relevance of the TIAs in terms of counterfeiting in the pharmaceutical sector were narrowed down to enforcement measures as well as sector-specific provisions with reference to the pharmaceutical sector. The challenge that seems to confront the current international and regional agreements is striking a balance between the focus on protection of intellectual property rights, as in ACTA, CPTPP, RCEP and CETA, ${ }^{52}$ and public health and safety objectives.

Unlike in other regional agreements, in the EU there is a clear bifurcation between, on the one hand, counterfeit medicines and, on the other, falsified medicines, a compartmentalization which is reflected in the legal instruments that address the issues of counterfeiting and falsification of medicinal products. The Enforcement Directive (Directive 2004/48/EC) ${ }^{53}$ and the Customs Regulation (Regulation 608/2013) (54 $^{5}$ contain, in addition to other broad provisions, measures that assist in dealing with counterfeit products (including medicines) while the Falsified Medicines Directive (Directive 2011/62/EU, hereafter 'FMD' $)^{55}$ specifically addresses falsification of medicinal products and contains a delimitation from considering any issues pertaining to counter-

52 P. Grootendorst and A. Hollis, The 2011 Canada-European Union Comprehensive Economic and Trade Agreement: an economic impact assessment of the EU's proposed pharmaceutical intellectual property provisions. Journal of Generic Medicines 8(2) (2011): 81-103.

53 Directive 2004/48/EC of the European Parliament and of the Council of 29 April 2004 on the enforcement of intellectual property rights. See Chapter 4 for more details.

54 Regulation (EU) No. 608/2013 of the European Parliament and of the Council of 12 June 2013 concerning customs enforcement of intellectual property rights and repealing Council Regulation (EC) No. 1383/2003; see Chapter 4 for more details.

55 Directive 2011/62/EU of the European Parliament and of the Council of 8 June 2011 amending Directive 2001/83/EC on the Community code relating to medicinal products for human use, as regards the prevention of the entry into the legal supply chain of falsified medicinal products. See Chapter 5 for more details. 
feiting of medicines, since counterfeiting is considered an IP issue. This almost watertight compartmentalization between matters that must be addressed under Medicines law or IP law or criminal law can give rise to practical difficulties of effective enforcement.

\subsection{IP Perspective}

The issue of enforcement of IPRs at the global scale was first considered seriously in the TRIPS Agreement. However, the provisions regarding the enforcement of IP rights in the TRIPS Agreement were not free from criticism, even at the incipient stage. ${ }^{56}$ The difficulties predicted in the discussions, such as the problematic and cumbersome process of bringing a dispute before the WTO, also subsequently came true. ${ }^{57}$ In fact, the US and the EU would have liked to have certain provisions regarding enforcement, such as border measures extending to all IP rights specified in the TRIPS Agreement, which did not take place. Consequently, most of the TIAs entered into by the US and the EU with other countries contain specific measures pertaining to enforcement. For instance, despite the criticism and failure of ACTA,${ }^{58}$ it did go a step further than TRIPS as it offered more concrete provisions and also addressed the element of cross-border infringements compared to TRIPS.

Looked at through the lens of cleaning the pharmaceutical sector of counterfeit products, it is apparent from the study of the TIAs that most of them deal specifically with the enforcement of IP rights. As a result, the focus is on the civil, criminal and border measures available to enforce the rights as well as to ensure the safety of products. Specifically regarding the pharmaceutical sector, the measures usually pertain to protection of patents, infringement of trademarks, copyrights and the traditional form of IP rights. For instance, Article

56 J.H. Reichman and D. Lange, Bargaining around the TRIPS agreement: the case for ongoing public-private initiatives to facilitate worldwide intellectual property transactions. Duke J. Comp. and Int'l L. 9(11) (1998) 34-39.

57 J. Watal, Is TRIPS a balanced agreement from the perspective of recent free trade agreements? In J. Drexl, H. Grosse Ruse and S. Nadde-Phlix (eds), EU Bilateral Trade Agreements and Intellectual Property: For Better or Worse. Springer (2014) 41-57.

58 D.S. Levine, Transparency soup: The ACTA negotiating process and 'black box' law-making. American University Journal of International Law and Policy 26(3) (2011):811; B. Mercurio, Beyond the text: the significance of the Anti-Counterfeiting Trade Agreement. Journal of International Economic Law 15(2) (2012): 361-390; A. Dür and G. Mateo, Public opinion and interest group influence: How citizen groups derailed the Anti-Counterfeiting Trade Agreement. Journal of European Public Policy 21(8) (2014): 1199-1217; C.R. McManis. The proposed Anti-Counterfeiting Trade Agreement (ACTA): two tales of a treaty. Hous. L. Rev. 46 (2009): 1235. 
9bis 2 of RCEP, ${ }^{59}$ which is closely reflected in Article 18.74 of the CPTPP, ${ }^{60}$ provides for the courts to use techniques such as taking into consideration lost profits and the market price or suggested retail price of goods in calculating damages for trademark or copyright infringement. Likewise, Article 18.74 and 18.77 of the CPTPP are mirrored in Articles 9bis 6 and 9quarter 6 of RCEP, concerning the destruction of infringed goods. These Articles also allow for the destruction of materials and implements employed in the creation of those goods. The criminal measures for the enforcement of IP violations proposed in ACTA have also been proposed in the CPTPP, under Article 18.77, and under Article 9quarter 1 of RCEP.

These measures propose to criminalize any copyright and trademark infringements that occurs on a 'commercial scale'. The TIAs do not specifically address the steps necessary to combat counterfeiting, although the goals of most TIAs reflect that counterfeiting and piracy need to be addressed and weeded out. ${ }^{61}$ In fact, it is highlighted in some of the preparatory documents ${ }^{62}$ that the IP law umbrella does not deal adequately with the issue of counterfeit medicine ${ }^{63}$ since it is considered an area of Medicines law. However, as Medicines law focuses its attention on the regulation of medicine and explicitly excludes IP matters, the problem of counterfeit medicine falls between the cracks of the otherwise strong and sound foundations of IP law and Medicines law. For instance, when addressing the issues of the pharmaceutical sector, IP law focuses on issues such as length of patents protection and trademarks protection of pharmaceutical companies. However, the solution to the problem of enforcement requires strong measures that need to be instituted to specifically address counterfeiting in the pharmaceutical sector.

A metaproblem with the multilateral and bilateral agreements (CETA and CPTPP) is the influence in the final agreement of the domestic set-up of the stronger party to the agreement. For instance, Canada and the US have a lower level of regulation but a higher level of punitive damages (in case of harm caused by the negligence of the manufacturer), compared to the EU where the emphasis is on a higher level of regulation towards prevention of harm.

\section{Article 9 RCEP.}

Articles 18.74 and 18.77 CPTPP.

${ }^{61}$ For example, Article 1(6) of the proposed TTIP states that the parties shall promote increased access to high-quality medicinal products, address the threat of antimicrobial resistance and fight against falsified medicinal products.

62 J.F. Morin, Sustainability Impact Assessment Relating to the Negotiation of the Intellectual Property Chapter of the Comprehensive Economic and Trade Agreement (CETA) between the EU and Canada. Université libre de Bruxelles (April 2011)

63 Oxfam Canada and Oxfam Québec. Submission regarding the Anti-Counterfeiting Trade Agreement.1; Essential Action, Letter to the Foreign Affairs and International Trade Canada (2 July 2009) 5. 
The most troubling scenario in multilateral agreements is when the process of alignment of regulation leads to lowering the level of regulation. ${ }^{64}$

Further, multilateral and bilateral agreements have sometimes been accused of projecting the agenda of 'expansion of power and influence'. The RCEP has been exalted as China trying to flex its muscles in the Asian region. ${ }^{65}$ These attempts by rich countries and their companies to steer domestic regulation through international trade agreements that supersede domestic laws ${ }^{66}$ may result in sacrificing the wider public interest. Bargaining autonomy in policy design, in trade-off for access to markets may be ill advised in many cases, especially when it is a question of public health and safety.

The bilateral, multilateral and plurilateral trade agreements are similar to a large extent because they mainly aim at strengthening and enhancing trade, investment and innovation by reducing barriers to trade, such as by reducing customs duties and by levelling the playing field for creative industries and innovators by providing protection to IPRs, among other measures. Besides the differences in geographical constellations, the degree of comprehensiveness of the agreements also varies. For instance, the CETA and CPTPP both reflect a common feature in bilateral and multilateral agreements, which is their analogous focus on the protection of IPRs under the umbrella of IP law. Even though the goal of public health and safety is recognized, the rules do not focus on provisions to be incorporated in Medicines law. The measures focus on how to make the sectors more competitive and reduce barriers to trade.

\subsection{Medicines Law Perspective}

The primary goal of Medicines laws has been safeguarding public health and safety, and, consequently, the legal provisions focus on ensuring quality, safety, efficacy and process of approval of medicines. The falsification of medicines has been extended serious attention only in the past decade. Therefore, it is not surprising that with reference to the pharmaceutical sector in the multilateral and bilateral agreements, the main aim of the agreements is to enable regulators to improve coordination for an increase in the safety and efficacy of

${ }^{64}$ O.B. Ronan, Moving Regulation out of Democratic Reach: Regulatory Cooperation in CETA and its Implications (No. 158). Kammer für Arbeiter und Angestellte für Wien, Abteilung Wirtschaftswissenschaft und Statistik (2016).

${ }_{65}$ CPTPP text and resources https://www.mfat.govt.nz/en/trade/free-trade -agreements/free-trade-agreements-in-force/cptpp/comprehensive-and-progressive -agreement-for-trans-pacific-partnership-text-and-resources/\#chapters.

${ }_{66}$ O.B. Ronan, Moving Regulation out of Democratic Reach: Regulatory Cooperation in CETA and its Implications (No. 158). Kammer für Arbeiter und Angestellte für Wien, Abteilung Wirtschaftswissenschaft und Statistik (2016). 
the pharmaceutical sector. The focus is primarily on three key areas of inspections, approvals and innovation. Inspections have the main goal of ensuring that the standards set are met in all countries and the global supply chain is secure. The multilateral agreements recognize that in the current global supply chains, different ingredients are sourced from different suppliers from all over the globe. ${ }^{67}$ Therefore, the necessity of securing the global supply chain is of utmost importance.

Secondly, the time spent on obtaining approval of medicines in different regions is of crucial importance for the patients as well as the pharmaceutical companies. For the patients, access to medicines can be a matter of life and death and the access hinges upon approval of the medicines. For the pharmaceutical companies, it is not only about putting their product on the market but also about resources spent on obtaining approval. If the method of procuring approval can be streamlined and becomes reciprocal in different parts of the globe, the manufacturers would be able to save resources. Therefore, the importance of aligning the approval of medicines in addition to coordination of inspections of companies producing medicines is usually stressed in bilateral and multilateral agreements.

The third common focus in the multilateral and bilateral agreements is on innovation in the context of the pharmaceutical sector. For instance, the erstwhile Transatlantic Trade and Investment Partnership (TTIP), now redundant, in Section 2.10 on pharmaceuticals stressed the importance of sharing expertise and findings and sharing views as regards the latest science. In CETA, the provisions directly focused on counterfeiting in the pharmaceutical sector include Articles 19-22, which cover cooperation against illicit drugs; law enforcement cooperation and the fight against organized crime and corruption; and money laundering and the financing of terrorism and cybercrime. ${ }^{68}$

Some of the controversial issues that need greater clarity pertain to the pricing of medicines, reimbursing bills, transparency of clinical trial data and protecting IP in the pharmaceutical sector. The EU explicitly maintained its position that no deal would be struck that would override the current legal

${ }_{67}$ European Commission, Inside TTIP, The Transatlantic Trade and Investment Partnership, towards an EU-US trade deal: an overview and chapter by chapter guide. Belgium, Section 2.10 Pharmaceuticals (2015) 31.

68 Council of the European Union. Comprehensive Economic and Trade Agreement between Canada, of the one part, and the European Union and its Member States, of the other part (14 September 2016). In Legislative Acts and other instruments. Inter-institutional File: 2016/0206 (NLE); see also European Council, Council of the EU, EU-Canada Trade Agreement: Council Adopts Decision to Sign CETA. Press Release 623/16 (28.10.2016). 
regime; however, uncertainty still exists regarding these issues and how they will finally be worked out. ${ }^{69}$

The need to enter into global as well as bilateral and multilateral agreements indicates that there is a palpable need for global consensus on how CFM should be addressed in concrete terms, because counterfeiting and falsification of medicines is a global problem and is not restricted to any one continent. Therefore, it is imperative to address counterfeiting and falsification of medicines at the national, regional and global level in order to safeguard the health and safety of people as well as protect businesses and innovation.

Going forward, it is important to look backwards with the intention of seeking inspiration for the future. Although ACTA failed, it had some worthy provisions for the institution of criminal measures which could be useful to take into account when the EU reconsiders that option. It must also be noted that many of the provisions of ACTA have been adopted or adapted in various bilateral and multilateral agreements, as well as in the EU legal instruments to a large extent. From the perspective of Medicines law, the Medicrime Convention, discussed in detail in Chapter 5, also has viable provisions for harmonization of criminal law.

In the absence of any global instrument, the various existing bilateral and multilateral agreements still broadly focus on removing trade barriers and promoting innovation. Dealing with counterfeiting and falsification of medicines does not occupy a place on global or regional agendas. It is important to point out that the strategy of employing local patchwork solutions to global problems has the drawback that the overall picture is not taken into consideration and the solutions are comparable to plugging the leaks in a pipe transporting water and not to replacing the corroded pipe. Eventually, the pipe will burst.

\section{INTERSECTION OF LAWS}

It is significant to investigate why the efforts made to combat counterfeiting and falsifications of medicinal products seem to be inadequate and insufficient. The reasons that will be elaborated in subsequent chapters can be narrowed down to one simple fact that seems to be ignored, namely that the problem of CFM lies at the intersection of Medicines law, IP law and criminal law, which address three different facets of the same problem (see Figure 1.1).

Firstly, many issues relating to counterfeiting of medicines concern the IP law area. For instance, within the EU a counterfeit or falsified medicine pack-

69 European Commission, Inside TTIP, The Transatlantic Trade and Investment Partnership, towards an EU-US trade deal:; an overview and chapter by chapter guide. Belgium, Section 2.10 Pharmaceuticals (2015) 32. 
aged in a manner aimed at imitating an authentic medicinal product would be considered falsified as well as counterfeit, if there is a trademark for that product. $^{70}$ Both the Trademarks Directive ${ }^{71}$ and the FMD contain provisions for addressing packaging of a product. While the FMD addresses the packaging of a falsified medicinal product, the Trademarks Directive relates to packaging of any product, which also includes medicinal products. Therefore, in the context of counterfeiting and falsification of medicine, it is always more than an IP rights violation, as the medicines sold in false packaging have inevitably been tampered with. ${ }^{72}$ In August 2017, the Danish Medicines Agency reported a counterfeit product, Xeplion $150 \mathrm{mg}$ (used to treat schizophrenia), ${ }^{73}$ which was discovered in the legal supply chain. This case illustrates how the provisions of Medicines law will usually find application besides IP law in cases of counterfeit and falsified medicines.

The second stream of law that deals with the problem of counterfeiting is Medicines law. In the EU, the FMD specifically and exclusively addresses the issues of falsified medicine and does not address the IP issues related to counterfeiting, which is categorically stated in the legal instrument. ${ }^{74}$ The line of demarcation between the Medicines law perception of a counterfeit medicinal product and the IP law perception of a counterfeit product is marked in the very name of the Directive, which uses the term 'falsified' rather than 'counterfeit'. The choice of 'term' is like opening a Pandora's Box and will be addressed in Section 4 below.

The third stream of law, besides IP law and Medicines law, that is crucial for dealing with counterfeiting and falsification is the area of criminal law. The role of national and transnational organized crime in the counterfeiting

70 See Article 1(1)(c) Directive 2011/62/EU of 8 June 2011 amending Directive 2001/83/EC on the Community code relating to medicinal products for human use, as regards the prevention of the entry into the legal supply chain of falsified medicinal products. OJ L 174, 1.7.2011, 74-87.

71 See Articles 10 and 11 of the Directive (EU) 2015/2436 of the European Parliament and of the Council of 16 December 2015 to approximate the laws of the Member States relating to trademarks. OJ L 336, 23.12.2015, 1-2.

72 An example is that of Herceptin, a cancer treatment drug being manufactured by Roche, which was intercepted in Germany in false packaging. It was later found out that the drug was manufactured in Italy and was stolen from an Italian hospital and was tampered with and reintroduced in the legal supply chain. See Chapter 2, Section 2, Operation Volcano.

73 Danish Medicines Agency. Withdrawal of One More Batch of Counterfeit Packs of the Schizophrenia Medicine Xeplion $150 \mathrm{mg}$. Retrieved from https:// laegemiddelstyrelsen.dk/en/news/2017/withdrawal-of-one-more-batch-of-counterfeit -packs-of-the-schizophrenia-medicine-xeplion-150-mg/ accessed 8 August 2017.

74 Recital 5 Directive 2011/62/EU. 
of medicines ${ }^{75}$ has been established. Further, the harmonization of criminal measures for combating counterfeiting has been discussed at various forums in the EU as well as at the international level. A proposal for a directive on criminal measures aimed at ensuring the enforcement of intellectual property rights (popularly known as IPRED II) ${ }^{76}$ was put forward in 2005, but withdrawn later. Another attempt to introduce criminal measures against acts of counterfeiting was made through ACTA, ${ }^{77}$ which was ultimately also unsuccessful. Yet another endeavour was made in 2011; the Medicrime Convention was proposed by the Council of Europe and by 24 July 2020 has been signed by many and ratified by at least 13 members of the Council of Europe. ${ }^{78}$ The Medicrime Convention's primary contribution is the criminalization of the act of counterfeiting of medicines. ${ }^{79}$

Since counterfeiting and falsification of medicines lies at the intersection of the three different streams of law (Figure 1.1), it necessitates coordination and cooperation between regulators, lawmakers and enforcers across the three spheres of law. Currently, any violation related to CFM is dealt with in a variety of ways depending upon where the problem is initially detected. If the medicines authorities detect the issue, Medicines law is applied and if the customs authorities discover the problem, IP law is drawn upon. If the proprietor of trademarks becomes acquainted with the violation first, then the proprietor would report the case to the police authorities and criminal law may be applied. Theoretically, it should not be difficult to earmark the areas that should be dealt with under a particular type of law. However, in practice it has been challenging because it is yet to be recognized that counterfeiting and falsification of medicines are two sides of the same coin. Any act of falsification of medicines essentially involves an act of counterfeiting, and hence, is a violation of IP laws as well. Therefore, it is neither prudent nor expedient to

75 See Chapter 2, Section 5.2, for more details. Also, see in Chapter 2, Section 2, Operation Volcano. The legitimate medicines were stolen from a truck supplying medicines to an Italian hospital by organized criminals, which were later tampered with and reintroduced in the legal supply chain. See also Chapter 2, Section 4, Operation Robin, where the organized structure of the criminal network was discovered. Similar examples have been witnessed in the US as well.

${ }_{76}$ The proposed Directive on criminal measures aimed at ensuring the enforcement of intellectual property rights (2005/0127/COD) was aimed at supplementing Directive 2004/48/EC.

77 Anti-Counterfeiting Trade Agreement, 2011.

78 Albania, Armenia, Belgium, France, Hungary, Spain, Moldova, Ukraine, Portugal, Russia, Turkey, Croatia and Switzerland have ratified the Medicrime Convention, from amongst the Members of the Council of Europe (Status as of 19 January 2020).

79 See Chapter 5 for more detailed discussion. 


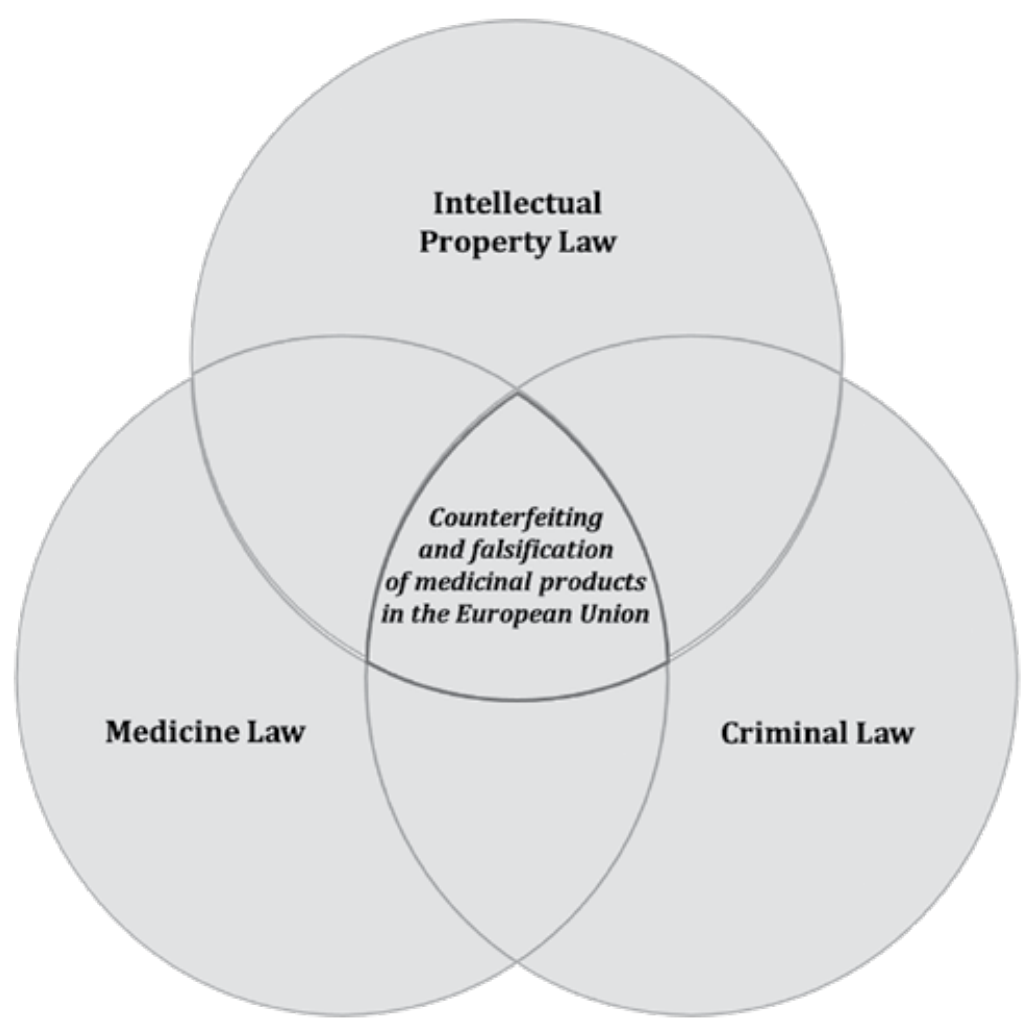

Figure 1.1 CFM at the intersection of laws

divide the responsibilities of the authorities representing the different streams of law into mutually exclusive watertight compartments.

Consequently, there is a risk that the right holder's or the aggrieved patient's complaints fail to be addressed because of a lack of understanding about counterfeiting and falsification being interlinked. A more serious result is that the people engaging in counterfeiting and falsification continue to take advantage of the weak state of the legal framework in the EU.

Due to ambiguity pertaining to what constitutes purely 'falsification' of a medicinal product and what entails 'counterfeiting' of a medicinal product, certain practical institutional problems also surface for health regulators, customs authorities and enforcement officers, leading to cases vacillating between the different authorities. Therefore, it is not always clear as to which State authority will lead the investigation of a case. For instance, in Operation 
Volcano, ${ }^{80}$ the Italian Medicines Agency led the operation, whereas, in Sweden, in the case of Operation Robin, ${ }^{81}$ it was the Swedish Customs and Law Enforcement Authority that steered the operation. Overall, the lack of clarity regarding institutional responsibility for dealing with the crime creates obstructions for an effective enforcement of the law concerning CFM.

While looking for solutions, it is necessary to address the problem of counterfeit and falsified medicines in a cohesive manner, taking into account all three spheres simultaneously. A violation of Medicines law concurrently presents associated infringement of IPR and the consequent illegal activity requires action by the police, activating the criminal law sphere. Therefore, a solution to the problem requires a commensurate and coordinated response from all three spheres of law.

\section{TERMINOLOGY}

While considering counterfeiting in the pharmaceutical sector, a number of terms are employed in the academic literature. The most frequently used terms are 'counterfeit' 82 'falsified', ${ }^{83}$ 'falsely labelled', ${ }^{84}$ 'substandard', ${ }^{85}$ 'spurious', ${ }^{86}$ 'fake', ${ }^{87}$ 'adulterated', ${ }^{88}$ 'illicit' and 'illegal'. It is important to clarify the meaning and scope of the different terms in order to address the problem

$80 \quad$ See Chapter 2, Section 2.

81 See Chapter 2, Section 4.

82 TRIPS: Agreement on Trade-Related Aspects of Intellectual Property Rights, 15 April 1994, Marrakesh Agreement establishing the World Trade Organization, Annex 1C, 1869 UNTS 299, 33 ILM 1197 (1994). Footnote 14 to Article 51; see Council of Europe. Council of Europe Convention on Counterfeiting of Medical Products and Similar Crimes Involving Threats to Public Health. Strasbourg (2011) (also known as the Medicrime Convention). Council of Europe Treaty Series. No. 211. See also Definition of a counterfeit drug, US Food, Drug and Cosmetic Act, 21 U.S.C. 321 Section 201(g)(2).

83 Article 1(1)(c) Directive 2011/62/EU.

84 WHO, Substandard/spurious/falsely labelled/falsified/counterfeit Medical Products: Report of the Working Group of Member States. Geneva. WHO (2012).

85 Ibid.

86 Ibid.

${ }_{87}$ M. Isles (2017). What's in a word? Falsified/counterfeit/fake medicines - the definitions debate (4 April 2017) https://doi.org/10.5301/maapoc.0000008; see also, as used by EMA, in public communications, for instance, European Commission, Buying Medicines Online, Think You Know What You Are Getting? Brussels. European Commission (2015).

88 A. I. Wertheimer and P.G. Wang, Counterfeit Medicines. Volume I: Policy, economics and countermeasures. ILM Publications (2012) 114. 
of counterfeiting and falsification in the pharmaceutical sector. Therefore, the different terms utilized are discussed in this section.

The term 'counterfeit' in general has been used for the goods that use an identical or confusingly similar trademark, without authorization, either on the goods or on the packaging of goods, in a manner that the rights of an authorized right holder are violated. ${ }^{89}$ This definition extends to all types of goods, including pharmaceutical products. This general understanding of the term has distilled into the EU legal instruments from the TRIPS Agreement. ${ }^{90}$ It is evident in the application of both the Enforcement Directive ${ }^{91}$ and the Customs Regulation. ${ }^{92}$ However, specifically, the term 'counterfeit medicine' is not defined in the EU legal instruments, except in the preamble to the FMD, which states that counterfeit medicines are construed to be the medicines that are in violation of IP laws. ${ }^{93}$ The Medicrime Convention, which has been signed and ratified by a few Member States of the EU, has defined counterfeit medicine as a 'medicinal product with a false representation regarding identity and/ or source'. ${ }^{94}$ The definition put forth by the Medicrime Convention is almost synonymous with the definition of a falsified medicinal product according to the FMD. ${ }^{95}$

Usually, the term counterfeiting is used in the context of IP law, as reflected in the Enforcement Directive and the Customs Regulation in the EU. However, at times, counterfeit can also be employed in the context of medicines with a false representation regarding identity and/or source, as indicated in the Medicrime Convention. ${ }^{96}$ The understanding of counterfeit and falsified medicines gets complicated, as the WHO continued to employ the term SSFFC (substandard, spurious, falsely labelled, falsified and counterfeit) ${ }^{97}$ until May 2017. In addition to 'counterfeit' and 'falsified', 'spurious' and 'falsely labelled' were introduced in the academic literature by this definition put forward by the WHO. However, in the latest policy document, distinctions have been made between substandard, unregistered/unlicensed and falsified

\footnotetext{
89 TRIPS Agreement. Footnote 14 to Article 51.

90 Ibid.

91 Directive 2004/48/EC of the European Parliament and of the Council of 29 April 2004 on the enforcement of intellectual property rights.

92 Regulation No. 608/2013/EU of 12 June 2013 concerning customs enforcement of intellectual property rights and repealing Council Regulation (EC) No. 1383/2003. OJ L 181, 29.6.2013, 15-34.

93 Recitals 5 and 29 Directive 2011/62/EU.

94 Article 4(j) Medicrime Convention.

95 Article 1(1)(c) Directive 2011/62/EU.

96 Article 4(j) Medicrime Convention.

97 WHO, Substandard/spurious/falsely labelled/falsified/counterfeit Medical Products: Report of the Working Group of Member States. Geneva. WHO (2012).
} 
medicinal products. The move to do away with the SSFFC definition and use only substandard and falsified as the terms of reference was approved by the World Health Assembly in May 2017. ${ }^{98}$ While spurious, falsely labelled and falsified medicines can be encompassed under the umbrella of falsified medicines and be addressed by Medicines law, 'counterfeit medicines' will usually fall under the umbrella of IP law. Therefore, the term 'counterfeit medicines' has been left out of the scope by the WHO, since the WHO only looks at the public health implications of medicinal products.

Besides the WHO (until May 2017) and the Medicrime Convention, there are a plethora of international organizations that continue to use the term 'counterfeit medicine' for what is known as 'falsified medicine' in the EU, such as the IRACM. ${ }^{99}$ Even the pharmaceutical companies prefer the general term 'counterfeit medicine'. ${ }^{100}$ In addition, many countries also still use the term 'counterfeit medicine', which the EU now calls 'falsified medicines'. For instance, the US Food and Drug Administration (FDA) uses the term 'counterfeit medicine' and not 'falsified' medicine. In fact, the FDA defines a counterfeit medicine as a fake medicine, which may be contaminated or contain the wrong dosage, and could be illegal. ${ }^{101}$ The term 'fake' medicine is also used in the awareness-raising campaigns conducted in the EU. The European Commission produced awareness-raising material ${ }^{102}$ regarding the new EU logo that is required to be affixed by all legitimate websites offering medicines for sale over the internet in the EU. Herein, the terms that are used include 'fake medicine', 'false medicine' and 'illegal medicine'. ${ }^{103}$ While the term 'fake' medicine is used by the US FDA to refer to 'counterfeit' medicines, in the EU, the term fake medicine is used to denote 'false medicine' that does not contain the active ingredient that is required in the medicinal product; or may contain harmful or lethal substances. ${ }^{104}$ Thus, the confusion regarding the most

98 WHO. Appendix 3, WHO Member State Mechanism on substandard/ spurious/ falsely labelled/ counterfeit (SSFFC) Medical Products Working Definitions. Geneva. WHO (2012).

99 IRACM, Counterfeit Medicines and Criminal Organisations. Paris. IRACM (2013).

100 See Sanofi, The Fight against Counterfeit Medicines. Press Book. Sanofi (May 2017). See also Roche, Position paper - Roche Position on Counterfeiting (April 2011, reviewed April 2017) 1-7.

101 US Food and Drug Administration, Counterfeit Medicine. Silver Spring. US Food and Drug Administration. Human Drug Information (2016).

102 European Commission, Buying Medicines Online, Think You Know What You Are Getting? Brussels. European Commission (2015).

103 Ibid.

104 Ibid. 
appropriate term continues among the regulatory authorities, where a counterfeit medicine can be understood as a fake medicine or a falsified medicine.

In addition to the above, the term 'substandard' medicine is also used in academic literature, ${ }^{105}$ as well as by the WHO. ${ }^{106} \mathrm{~A}$ substandard medicine, also known as an 'out of specification' (OOS) product, is perceived to be a medicine that is an original product manufactured by an authorized manufacturer but may not live up to the requirements of the national medicines regulatory authority. A substandard drug is no less dangerous than a falsified medicine. ${ }^{107}$ Another term that is frequently used in academic literature and is sometimes confused with counterfeit/falsified medicines is 'adulterated' medicines. An adulterated medicine is one in which the composition of the medicine is altered by the deliberate addition of a component that is not ordinarily a part of that substance, which usually leads to the debasement of that substance. ${ }^{108}$

Further, there are two umbrella terms that are also commonly used in the context of counterfeit and falsified medicines, which are 'illicit medicines' and 'illegal medicines'. Usually, these medicines may or may not be medicines that are authentic but appear in the illegal supply chain. In other words, illegal and illicit ${ }^{109}$ medicines refer to the channel of trade rather than the quality of the medicinal product in question. However, these medicines may be counterfeit and falsified. In the EU, for instance, illegal medicines have been referred to as either counterfeit or fake medicine. ${ }^{110}$

It is necessary to emphasize that authentic and original medicines can also be found in the illegal supply chain. The reason for their appearance in the illegal supply chain is usually linked to lack of required authorizations and approvals because of the non-fulfilment of requirements of the national competent authorities' (NCAs') provisions. Therefore, it will be incorrect to state that all illegal and illicit medicines are counterfeit medicines. Likewise, it needs to be reiterated that substandard drugs are not counterfeit drugs. They

105 A. Attaran, D. Barry, S. Basheer, R. Bate, D. Benton, J. Chauvin and P.N. Newton, How to achieve international action on falsified and substandard medicines. BMJ 345 (2012): e7381.

106 WHO. Appendix 3, WHO Member State Mechanism on substandard/spurious/ falsely labelled/ counterfeit (SSFFC) Medical Products Working Definitions. Geneva. WHO (2012).

107 A. Johnston and D.W. Holt, Substandard drugs: a potential crisis for public health. British Journal of Clinical Pharmacology 78(2) (2014): 218-243.

108 Miller-Keane, Encyclopedia and Dictionary of Medicine, Nursing, and Allied Health (seventh revised edition). London. Elsevier Health Science Inc. (2009).

109 UNODC, Terminology and Information on Drugs (third edition). Vienna. UNODC (2016).

110 European Commission, Buying Medicines Online, Think You Know What You Are Getting? Brussels. European Commission (2015). 
are authentic drugs, manufactured by authorized market authorization holders. They are considered substandard because they do not meet the requirements of the NCAs.

It is apparent from the foregoing discussion that clarification of the terminology that is used in the context of counterfeit and falsified medicines is important. At the EU level, there is an apparent agreement that the IP law perspective of counterfeiting revolves around the enforcement of the private rights of the right holders of a trademark. In other words, the term counterfeiting indicates only IP violations and infringements, ${ }^{111}$ and the public health and safety aspect is not dealt with. For instance, as regards the definition of 'counterfeit goods' in the Customs Regulation, ${ }^{112}$ the focus is on infringement of trademarks.

On the other hand, whenever the term 'falsified medicine' is employed, the health and Medicines law perspective comes into play, whereby the public law perspective of safeguarding public health and safety as the primary goal takes the centre stage. The FMD defines a falsified medicine and focuses on the identity, sources and history of the medicinal product. The FMD clearly leaves out the IP law-related aspects, ${ }^{113}$ because it differentiates between counterfeit medicines and falsified medicines. ${ }^{114}$

When law and policy documents and academic literature use the terminology interchangeably, not only does it lead to confusion, but it also has a bearing on how the authorities interpret a particular offence. The interpretation of the offence would subsequently determine the applicable law. Whether it would be IP law or Medicines law would depend upon the type of violation. For instance, if fake packaging material is intercepted it is an IP infringement, as it is a violation of the right holder's right with respect to trademark rights. ${ }^{115}$ However, the crucial link between IP violation and Medicines law violation is that a trademark violation, which is of the nature of false packaging, is also a violation of the FMD, Article 1(1)(c). ${ }^{116}$ In this way, an IP violation related to pharmaceuticals is closely linked to a violation of Medicines law.

In this book, the term, 'falsified medicine' will be used in the context of the FMD and the term 'counterfeit medicine' will be used in the context of the Enforcement Directive and Customs Regulation, as determined by the respective legal instruments.

111 As used in, for instance, Article 2(5) Regulation 608/2013. See also Recital 5 of Directive 2011/62/EU.

112 Article 2(5) Regulation 608/2013.

113 See Article 1(1)(c) Directive 2011/62/EU.

114 Recital 5, preamble of Directive 2011/62/EU.

115 See Articles 10 and 11 Directive (EU) 2015/2436.

116 See Article 1(1)(c) Directive 2011/62/EU. 
The far-reaching impact of counterfeiting and falsification of medicinal products has been observed over a large cross-section of society, especially on patients, the pharmaceutical industry and States. The patients are directly affected since their access to safe, effective and good quality drugs is hindered. They stand to suffer a direct loss, ranging from not being cured of the disease, to building drug resistance, to losing their life and, thus, becoming the ultimate victims of falsification and counterfeiting of medicinal products. The pharmaceutical industry is also vulnerable to falsification and counterfeiting of medicinal products. Since the pharmaceutical companies invest in innovation, research and development, run clinical trials, manufacture drugs and apply for authorizations and approvals, ${ }^{117}$ the pharmaceutical industry lobbies for a competitive business environment and safeguards against counterfeit products that are a threat to its reputation and goodwill. The national State authorities also confront challenges because of falsification and counterfeiting of medicinal products, particularly since the States need to prioritize the protection of public health and safety, ${ }^{118}$ as well as ensure the maintenance of affordable prices of medicines for the general public. Consequently, each of these stakeholders has a vested interest in combating counterfeiting and falsification of medicinal products.

The main focus of this book is to present a holistic picture of the problem concerning the regulation of counterfeit and falsified medicinal products ${ }^{119}$ in the EU. At first, the problem of counterfeiting and falsification is explained and contextualized. This is followed by an illustration of the practical manner in which counterfeiting and falsification occurs in the pharmaceutical sector by introducing three case studies. Thereafter, the relevant legal instruments are analysed in the light of the case studies.

Primarily, two questions are investigated. Firstly, how is counterfeiting and falsification of medicinal products addressed by the law (the FMD (Directive 2011/62/EU), the Enforcement Directive (Directive 2004/48/EC) and the Customs Regulation (Regulation 608/2013)) in the EU (de lege lata).

\footnotetext{
117 G. Permanand, EU Pharmaceutical Regulation the Politics of Policy-Making. Manchester University Press (2006).

118 See Article 168 TFEU.

119 A medicinal product is understood, as defined in Article 1(2) of Directive 2001/83/EC, to mean any substance or combination of substances that have the properties for treatment or prevention of disease in human beings. The definition of a medicinal product also includes any substance or a combination thereof that may be employed in administering the substances with the goal of restoring, correcting or modifying physiological functions.
} 
Secondly, it is assessed whether the law containing tools to combat counterfeiting and falsification of medicinal products is adequate.

The book establishes that counterfeiting and falsification of medicines lies at the intersection of Medicines law, IP law and criminal law. In the EU, the FMD (Directive 2011/62 /EU) governs the falsification of medicinal products whereas counterfeit medicinal products are dealt with under IP law (Directive 2004/48/EC and Regulation 608/2013). However, criminal law is not yet harmonized in the EU.

Although it is recognized that the perspective of each stakeholder group - patients, the pharmaceutical industry and the State - is significant, in this book, the focus is predominantly on the legal instruments that are employed to combat the falsification and counterfeiting of medicinal products at the EU level.

\section{6}

DELIMITATION

Counterfeiting and falsification in the pharmaceutical sector is a worldwide problem. However, this book concentrates on counterfeiting and falsification in the pharmaceutical sector in the EU. The book focuses on the acts of counterfeiting and falsification that target IP protected medicinal products. Perhaps, it is also important to specify that while exploring IP law, the focus is not on substantive law. The detailed provisions of, for instance, trademark law, will therefore not be addressed. However, an overview of the enforcement of IP law in the EU, particularly with respect to enforcement of trademarks, which is directly relevant to counterfeiting of medicines, will be explored.

It needs to be recognized that falsification and counterfeiting of medicinal products has only been accorded serious attention by lawmakers in the past two decades in the EU and as a result, the case law and scholarly works available on this subject are limited.

An important fact worthy of acknowledgement is that counterfeiting is intrinsically an illegal activity. An obvious consequence is that it is difficult to accurately account for this activity, which is primarily conducted in the dark. As a result, any statistics and figures that represent CFM are not exact. At best, these statistics can provide a rough estimate, and in all likelihood, the reality is greater and more widespread than comes across in the various reports, statistics and data. Therefore, even though all the figures and statistics are gathered from reputable sources like the OECD, WHO, Interpol and Europol, these must only be seen as indicators.

There is a negligible amount of case law, trustworthy empirical data and statistics on the topic of counterfeiting and falsification of medicines because it is intrinsically a fast moving, behind-closed-doors type of illegal activity that leaves hardly any paper trail. In one of the case studies in Chapter 2, 
reliance is therefore placed on a report, the White Paper on Operation Volcano written by the Italian Medicines Agency together with medicine agencies of other Member States. For the other two case studies, reliance was placed on case law. These legal case studies were supplemented by discussions with representatives of the medicines agencies of Italy and the UK, and the head of investigations of Operation Robin of the Customs and Law Enforcement Authority in Sweden. The case law was supplemented by confidential case notes and preparatory documents that were made available.

As we will discover, the act of counterfeiting and falsification of medicinal products is generally accompanied by associated crimes like money laundering, smuggling, theft, forgery of documents, fraud and IP violations. ${ }^{120}$ Even though exploration of these associated crimes is relevant and important, the focus remains solely on the crime of counterfeiting and falsification of medicinal products. The accompanying crimes are mentioned but not explored further.

Another general consideration is that the anti-counterfeiting measures are deduced from the three core relevant legal instruments, viz. the Enforcement Directive, the Customs Regulation and the FMD, none of which aim at explicitly weeding out counterfeit medicines from the EU. The FMD states that it does not aim to combat counterfeiting but only to remove falsified medicines from the legal supply chain, whereas the Enforcement Directive and the Customs Regulation deal with enforcement of IP rights. Although the Enforcement Directive and the Customs Regulation recognize that counterfeiting and piracy is a problem, they do not have an expressed goal of combating counterfeiting and piracy.

\section{ANATOMY OF THE BOOK}

In order to achieve the objectives of the book, which are to analyse how the law (Directive 2011/62 /EU, Directive 2004/48 /EC and Regulation 608/2013) in the EU addresses counterfeiting and falsification of medicinal products, and to analyse whether the law that contains tools to combat counterfeiting and falsification of medicinal products is adequate, the book is structured as follows:

Chapter 1 introduces the book. It presents the relevance of the book and states the parameters and objectives that are hoped to be achieved. It consists of a discussion of terminology highlighting the intricacies, challenges and confusion caused by the use of different terminology pertaining to counterfeiting and falsification of medicines. Further, it analyses how the problem of

120 See Chapter 2, Sections 3 and 4, Operation Singapore and Operation Robin, for more details. 
counterfeiting and falsification of medicinal products has been and is being tackled at the global level. It establishes that the book stands at the intersection of IP law, Medicines law and criminal law.

Chapter 2 of the book illustrates the problem of counterfeiting and falsification of medicinal products. By setting the context and providing an insight into real-life examples through case studies, the gaps in the legal framework dealing with counterfeiting in the EU emerge. Three operations are discussed in this regard - Operation Robin, Operation Singapore and Operation Volcano. These operations highlight the problems associated with overlapping and intersection between IP law and Medicines law, along with the lack of criminal sanctions and penalties. Common issues of concern are identified in Chapter 2, such as the inability to keep the legal supply chain clear of infiltration by the illegal supply chain and insufficient control over the online sale of counterfeit medicine.

In Chapters 3, 4 and 5 an analysis of the legal instruments is conducted in the light of the issues identified in Chapter 2. Chapter 3 entails an analysis of the FMD, with focus on the legal supply chain, the online sale of medicines and the safety of medicinal products. In Chapter 4, the Enforcement Directive is analysed, with special emphasis on the provisions for enforcement of IP as well as those issues that have not been addressed. The Customs Regulation is also discussed in Chapter 4, wherein the analysis of the Customs Regulation is carried out with special reference to measures that may be taken by the authorities at the borders to prevent entry of CFM. This is followed by Chapter 5 on criminal law, which highlights the lack of common provisions, underlines the potential of the Medicrime Convention, and evaluates the impact of the same on the current state of affairs.

The final chapter of the book, Chapter 6, summarizes the book and presents recommendations for dealing more effectively with the problem of counterfeiting and falsification of medicines. 